Doi: 10.22478/ufpb.1983-1579.2018v1n11.28548 http://periodicos.ufpb.br/ojs2/index.php

\title{
CURRÍCULO POR PROJETOS: repercussões para a inovação na Educação Superior e no Ensino de Engenharia
}

\section{CURRICULUM BY PROJECTS: impacts for an innovation in Higher Education and Engineering} Education

\author{
Elize Keller-Franco ${ }^{1}$ \\ Marcos Tarciso Masetto ${ }^{2}$
}

\begin{abstract}
Resumo: A educação superior na atualidade tem sido alvo de diferentes demandas e expectativas. Destacase hoje a necessidade urgente de repensar as concepções de ensino em consonância às novas relações sociais, econômicas e políticas, preparando os jovens para uma efetiva participação no mundo do trabalho e no direito à cidadania e formação plena. No entanto, predominam no cenário universitário, currículos organizados sob abordagens tradicionais. O presente trabalho trata dessa questão colocandose como objetivo trazer para análise e reflexão o potencial de uma organização curricular por projetos constituir-se em uma inovação na educação superior e, por conseguinte, no ensino de Engenharia. Para isso, trazemos uma pesquisa qualitativa desenvolvida em uma instituição de Ensino Superior que desenvolve uma organização curricular alternativa e uma proposta pedagógica baseada em projetos e a partir desse estudo em diálogo com a produção acadêmica sobre o currículo por projetos na formação de engenheiros, discute-se o potencial deste currículo para criar novos cenários na educação em engenharia. Considera-se que a implementação do currículo por projetos é relevante para perspectivar práticas pedagógicas inovadoras quando se pretende um processo ensino aprendizagem que favoreça princípios tais como; abordagens interdisciplinares do conhecimento, articulação entre teoria e prática, integração com o contexto social e situações reais do mundo do trabalho, desenvolvimento da autonomia do estudante na gestão da aprendizagem, dentre outros.
\end{abstract}

Palavras-chave: Projetos. Currículo. Educação superior. Ensino de Engenharia
Abstract: Higher education nowadays has been the target of different demands and expectations. The urgent need to rethink conceptions of education in line with the new social, economic and political relations, preparing young people for effective participation in the world of work and the right to citizenship and full training stands out today. However, curricula organized under traditional approaches predominate in the university setting. The present work deals with this question aiming to bring to analysis and reflection the potential of a curricular organization based on projects to be an innovation in higher education and, therefore, in Engineering teaching. To that end, we bring a qualitative research developed in a Higher Education institution that develops an alternative curricular organization and a pedagogical proposal based on projects and from that study in dialogue with the academic production on the curriculum by projects in the training of engineers, the potential of this curriculum to create new scenarios in engineering education. It is considered that the implementation of the curriculum by projects is relevant to the perspective of innovative pedagogical practices when it is intended a learning teaching process that favors principles such as; interdisciplinary approaches to knowledge, articulation between theory and practice, integration with the social context and real situations of the world of work, development of student autonomy in the management of learning, among others.

Keywords: Projects. Curriculum. Higher Education. Engineering teaching.

\footnotetext{
${ }^{1}$ Doutora em Educação pela Pontifícia Universidade Católica de São Paulo. É Docente no curso de Pedagogia e no Mestrado do Centro Universitário Adventista Engenheiro Coelho. E-mail: elizekeller@gmail.com. Orcid: http://orcid.org/0000-0003-1795-8947.

${ }^{2}$ Doutor em Psicologia Educacional pela ontifícia Universidade Católica de São Paulo e Livre Docente em Didática na Pontifícia Universidade Católica de São Paulo. E-mail: mmasetto@gmail.com. Orcid: https://orcid.org/oooo0002-9892-3959.
} 


\section{INTRODUÇÃO}

Tem sido recorrente nos estudos recentes relativos à Educação Superior (ZABALZA, 2004; MASETTO, 2011, 2012) a denúncia de que as instituições universitárias não vêm atendendo de modo eficaz a formação geral, constituída de conhecimentos, habilidades e atitudes relevantes para a formação científica e cultural do aluno, nem a formação profissional que integra as capacidades técnicas da ocupação aos valores éticos e humanísticos exigidos pela sociedade atual, impondo uma revisão nas suas formas de organização, finalidades e práticas.

O conjunto das novas referências sociais e pedagógicas capazes de alterar o modelo tradicional de formação apontam para abordagens integradas do conhecimento, referenciais epistemológicos que valorizam a construção do conhecimento a partir de problematizações sociais e profissionais concretas, indissociabilidade entre ensino, pesquisa e extensão, relações dialógicas no processo ensino-aprendizagem e avaliação, valorização das dimensões conceituais, procedimentais e atitudinais dos objetivos e conteúdos de aprendizagem, enfim, para a formação integral da pessoa humana.

Temos, portanto como desafio investigar desenhos curriculares que ajudem a concretizar tais expectativas. Neste trabalho, utilizamos parte da discussão teórica e dos dados elaborados para a dissertação de Mestrado (KELLER-FRANCO, 2008) que teve como objetivo analisar a possibilidade de uma organização curricular por projetos se constituir em uma proposta inovadora na educação superior. Um estudo teórico sobre currículo e sobre projetos deu origem às categorias analíticas. A pesquisa de campo teve lugar na Universidade Federal Paraná- campus Litoral, instituição esta que desenvolve uma organização curricular alternativa e uma proposta pedagógica baseada em projetos. Os dados levantados a partir de entrevistas, observação e análise de documentos levaram a elaboração das categorias empíricas. A partir dessa pesquisa em diálogo com estudos produzidos na engenharia (FERNANDES, FLORES e LIMA, 2010; ANDERSEN, 2011; WENK E BLIJ, 2011; HATTUMJANSSEN, 2011) se analisa e discute o potencial do currículo por projetos para idear práticas educacionais inovadoras nessa área.

\section{SENTIDO E ORIGEM DA APRENDIZAGEM BASEADA EM PROJETOS}

Para Boutinet (2002), assiste-se a uma proliferação de expressões e siglas para designar o recurso ao projeto no campo da educação, sem que haja questionamento e clareza suficiente sobre os significados e usos que lhe são associados. Tal diversidade nos remete à necessidade de revisar a fundamentação e o significado de projeto enquanto intervenção metodológica a serviço do processo ensino-aprendizagem, para que possamos refletir sobre suas implicações para uma organização curricular por projetos.

O trabalho com projetos não é novo na educação. Podemos situá-lo como uma prática pedagógica que obteve reconhecimento em diferentes momentos e movimentos educacionais. Sua origem nos reporta a segunda metade do século XVIII com dois educadores norte-americanos, John Dewey e seu aluno William Kilpatrick.

Dewey (1959) faz uma denúncia ao estado de compartimentalização enfrentado pela escola mediante a multiplicação de matérias, cada qual sobrecarregada de fragmentos desconexos, distanciados da vida real e que deveriam ser assimilados pela repetição. Propõe como alternativa as "ocupações construtivas" que foram ganhando espaço e tornaram-se conhecidas como projetos. Kilpatrick deu prosseguimento às ideias de Dewey.

A busca dos fundamentos conceituais da metodologia de projetos nos leva a corrente filosófica do pragmatismo norte-americano e a teoria educacional progressivista. O pragmatismo concebe 0 mundo em constante transformação. Enfatiza o conhecimento fundamentado na experiência e defende que o ser humano tem uma mente ativa e exploratória. O trabalho com projetos é um dos métodos favoritos dos pragmatistas. Dewey é um dos principais representantes dessa corrente filosófica.

A teoria educacional que recebeu forte influência do pensamento filosófico pragmático foi o progressivismo. Consequentemente, esta teoria educacional defende princípios, do ponto de vista 
epistemológico, com relação ao papel do aluno e do professor, à metodologia e ao currículo, muito próximos do posicionamento pragmático. William Kilpatrick está entre os educadores mais empenhados em aplicar a teoria educacional progressivista, daí o fato de ser ele considerado um dos precursores do método de projetos (KNIGHT, 2011).

Segundo Hernandez (1998), os projetos em sua primeira versão caracterizavam-se pela ideia de partir de uma situação problemática, vincular a aprendizagem ao mundo exterior e oferecer uma alternativa à fragmentação das matérias.

A teoria educacional progressivista perdeu sua influência em meados da década de 1950, consequentemente os projetos que gozavam de prestígio nessa abordagem educacional também perderam sua influência. Hernández (1998) aponta ainda a racionalidade tecnológica que se configurou como ideologia dominante após a Segunda Guerra, como responsável pelo congelamento do uso de projetos.

Para esse autor, os projetos voltaram a despertar interesse a partir da metade dos anos 60 do século XX, ficando conhecidos de forma mais usual pelo nome de "trabalho por temas". Para Hernández (1998) as ideias de Piaget sobre o desenvolvimento da inteligência e sua relação com a aprendizagem de conceitos despertaram a indagação sobre que conceitos aprender e quais os critérios para selecioná-los. Em resposta, Bruner (1976) propôs a noção de conceitos-chave, que orientariam a organização de eixos conceituais, com o mesmo significado de grandes temas, ou temas aglutinadores. Os projetos ou o trabalho por temas se mostraram como um caminho para abordar essa proposta na sala de aula. A proposta de Bruner desperta a noção de um currículo interdisciplinar, já que várias disciplinas têm conceitos-chave em comum.

Nos anos 90, a metodologia de projetos é revalorizada, pois coincide com as propostas curriculares atuais que buscam levar o aluno a pensar criticamente, a dar significado à informação ao aplicá-la para planejar ações, resolver problemas, criar novos materiais e ideias, envolvendo-se ativamente na aprendizagem. "Numa proposta relativamente recente, a utilização de projetos num processo pedagógico aparece com o sentido de proposição de uma prática pedagógica crítica, reflexiva e problematizadora" (BEHRENS, 2004, p.167).

\section{TRABALHO COM PROJETOS COMO ANCORAGEM PARA UM PARADIGMA CURRICULAR ALTERNATIVO NA EDUCAÇÃO SUPERIOR}

Localizada a origem e o sentido do trabalho com projetos, busca-se situá-lo enquanto teoria curricular. O resgate das características definidoras do trabalho com projetos em diálogo com o pensamento curricular (SILVA, 2007; LOPES E MACEDO, 2011) permitiu situar o currículo por projetos num movimento cuja origem se situa na linha filosófica do pragmatismo e na tendência pedagógica progressivista de Dewey e Kilpatrick, evoluindo na atualidade para uma tendência curricular crítica, organizando-se sob as pressuposições do código curricular integrado.

As teorias críticas surgem no início da década de setenta como uma reação à concepção curricular tradicional, de ênfase tecnicista, burocrática e administrativa, inspirada nos modelos de administração taylorista. A abordagem curricular crítica desloca a ênfase centrada nos aspectos técnicos de como organizar e elaborar o currículo limitado ao âmbito pedagógico, ampliando a análise para uma perspectiva sociológica em suas determinações e conexões com as estruturas econômicas e sociais mais amplas e com as relações de poder.

O currículo integrado tornou-se conhecido a partir de Basil Bersntein (1995). No currículo integrado as fronteiras entre as áreas do conhecimento são menos nítidas. A organização do conhecimento se dá a partir de uma ideia central relacionadora, em vez de disciplinas isoladas. A abordagem curricular integrada não subestima o papel das disciplinas, mas propõe novas relações para além da dominante organização disciplinar. Conforme Beane, na integração curricular "o conhecimento proveniente das disciplinas reposiciona-se no contexto do tema, questões e nas 
atividades em causa" (BEANE, 2003, p.106). Para Santomé (1998) uma das modalidades mais clássicas de integração curricular se dá por meio do trabalho com projetos.

Localizado dentro de um marco teórico conceitual, à medida que se avançou na pesquisa exploratória as categorias analíticas constituídas do conjunto de elementos inovadores viabilizados em um currículo por projetos foram emergindo.

A pesquisa de campo teve como cenário a Universidade Federal do Paraná, Setor Litoral, instituição sediada no Brasil que vem desenvolvendo uma organização curricular alternativa e uma proposta pedagógica fundamentada em projetos. Os dados coletados a partir de entrevistas, observação e análise documental deram origem às categorias empíricas. O quadro abaixo sintetiza e permite uma análise comparativa entre as categorias analíticas e empíricas. Os indicadores de um currículo organizado por projetos propostos nas categorias e subcategorias analíticas se repetiram nas categorias e subcategorias empíricas, alguns de forma mais evidente outros de forma mais silenciada (setas mais claras). Novos indicadores emergiram na pesquisa de campo vindo a ampliar as categorias inicialmente propostas, como, por exemplo, a autonomia, antecedentes culturais e a parceria com a comunidade e instituições sociais e governamentais, não previstas inicialmente nas categorias analíticas. 
Quadro 1 - Elementos viabilizados em um currículo por projetos.

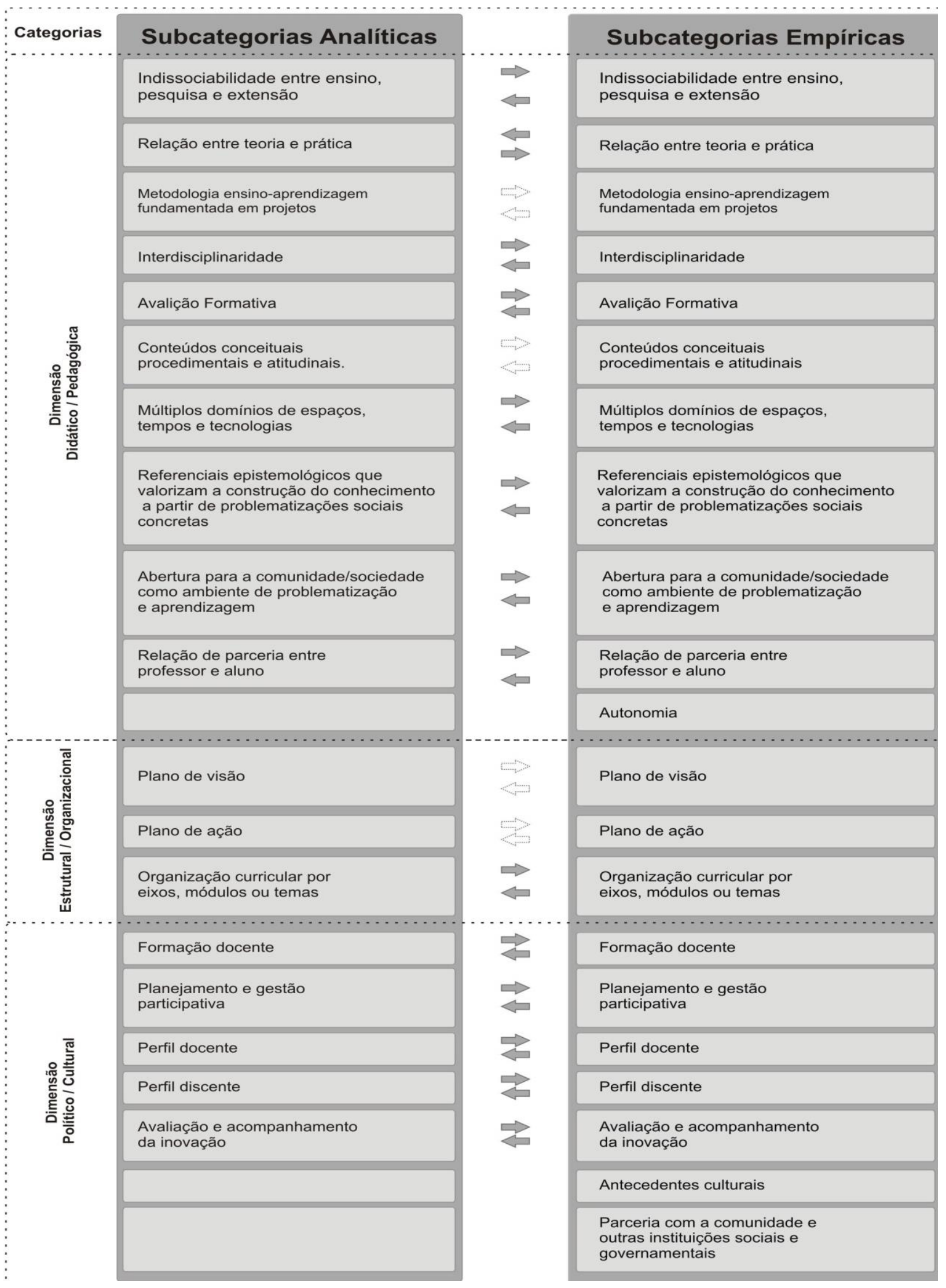


Uma descrição e análise mais detalhada sobre os elementos inovadores do currículo por projetos podem ser encontrados em Keller-Franco (2008).

\section{DESENHO DE UMA ORGANIZAÇÃO CURRICULAR POR PROJETOS}

São pouco frequentes na literatura e na prática, orientações para o desenho de um currículo por projetos. Nas experiências em andamento encontram-se formas e concepções variadas, algumas instituições mantém o currículo tradicional e dedicam parte da carga horária para o desenvolvimento de um projeto que pretende ser interdisciplinar. Na concepção que defendemos, os projetos não ocupam uma parte do currículo organizado sob a concepção e desenho curricular disciplinar, mas, todo o currículo é organizado em projetos interdisciplinares. Tal organização exige uma mudança de paradigma. Moesby (2004) ressalta que liberar as disciplinas e organizar o processo ensinoaprendizagem em torno dos projetos é o processo de mudança mais difícil na ressignificação curricular, sendo que muitas instituições jamais alcançarão esse nível.

Apresentamos a seguir diferentes níveis de implementação do trabalho com projetos até se constituir em um novo paradigma curricular, tendo como base os níveis propostos por Moesby (2004) preservadas algumas adaptações de autoria nossa.

Um primeiro nível refere-se ao uso do projeto enquanto metodologia. Essa utilização independe de uma decisão institucional, cada professor, nos limites da sua disciplina utiliza o trabalho com projetos. A nova prática é encaixada no modelo tradicional de currículo. Essa abordagem traz como vantagem uma participação mais ativa do aluno na construção do conhecimento, mas, por outro lado, pode sobrecarregá-los se vários professores resolverem aplicá-la.

Em um nível crescente, duas ou mais disciplinas se unem para trabalhar um projeto comum. Este estágio pede a colaboração entre os docentes e as disciplinas. Não se percebe alteração na organização tradicional do trabalho escolar, mas, uma cultura colaborativa está em processo de criação. A inovação começa a sair do nível individual para adentrar no nível grupo/ sistemas. Nesse estágio começa a haver um desconforto com o currículo disciplinar. Áreas que partilham conceitos se encontram em semestres diferentes, dificultando a integração.

O terceiro estágio já representa uma mudança curricular, mas em nível muito simples. O projeto recebe um espaço formal no currículo, constituindo-se num componente curricular, embora a concepção de currículo que o orienta ainda seja o paradigma curricular dominante disciplinar-técnicolinear.

No próximo estágio, o projeto é o foco e não os conteúdos disciplinares. Os conteúdos disciplinares entram para alimentar os projetos. O currículo é repensado para priorizar o projeto e mais tarde são escolhidas as disciplinas que favoreçam o alcance dos projetos e a performance dos alunos. Essa mudança já atinge o nível institucional e representa uma mudança curricular significativa, o projeto é o centro do currículo e não as disciplinas. Neste nível a instituição passa por uma mudança considerável na forma de abordar e administrar o processo ensino-aprendizagem. Pode se dizer que é um período de transição em direção a um novo paradigma curricular.

No quinto nível as disciplinas deixam de existir, o currículo se estrutura por eixos compostos pelos projetos, pelos fundamentos teóricos práticos e pelos conteúdos socioculturais. Estes últimos entendidos como questões relevantes extraídas da realidade dos envolvidos, tendo em vista levá-los a tomar consciência da sua realidade e a agir para transformá-la. Na medida do possível os eixos mantêm comunicação. Poderíamos dizer que esse nível contempla duas alterações básicas para a desconstrução do paradigma curricular vigente: a estrutura curricular disciplinar e a noção de conhecimento distanciado dos contextos sociais. Professores e alunos precisam desenvolver uma nova cultura para trabalhar nessa proposta e a instituição necessita de uma compreensão mais abrangente da organização e utilização do conhecimento.

No último e mais alto nível, na condição de um novo paradigma, o currículo se estrutura em torno de projetos que integram áreas de conhecimento que mantêm semelhanças importantes no que 
diz respeito a conteúdos, conceitos, procedimentos, métodos de pesquisa, etc. Os projetos organizam-se sob o guarda-chuva de um grande tema ou eixos temáticos que delimitam e direcionam o foco para o qual deve convergir a formação em suas dimensões conceituais, procedimentais e atitudinais. A organização e desenvolvimento de um currículo por projetos não elimina a existência de conhecimentos disciplinares, mas reposiciona-os, reúne-os novamente, rompendo com as fronteiras disciplinares e com a compartimentalização do conhecimento ao integrar saberes e conceitos-chave de diferentes recortes disciplinares e ampliá-los a partir da consideração e da inclusão de conteúdos do mundo vivencial.

Esse último nível é compatível com a concepção de currículo por projetos que vimos defendendo aqui. Os projetos não são uma parte do currículo, mas, todo o currículo se desenvolve em torno dos projetos. Tal organização curricular exige uma mudança de paradigma. Por alterar as estruturas de base da educação, por mexer com paradigmas solidificados e arraigados, esse nível de inovação curricular impacta não somente sobre toda instituição educacional, como também sobre os variados segmentos da sociedade que abrigam expectativas sobre a educação sob uma visão regida pela lógica utilitarista, própria de um sistema capitalista, cuja ideologia educacional propõe uma formação que se restringe ao desempenho de uma ocupação.

A construção de um desenho curricular integrado, especialmente o currículo por projetos, requer uma série de condições. Anterior a elaboração da arquitetura curricular, é preciso refletir sobre as razões que orientaram a opção por essa modalidade de currículo, tendo a clareza que mais do que um arranjo técnico, trata-se de uma filosofia curricular. Masetto (2004) faz o oportuno alerta de que a compreensão clara e completa de um paradigma ou de uma proposta educacional nos permite analisála criticamente, assumi-la integralmente, fazer determinadas adaptações, ou mesmo propor outra que, em nosso modo de ver, melhor responde às concepções, expectativas e preocupações educacionais que temos. No caso de aceitarmos o paradigma temos competência para implementá-lo corretamente.

\section{POTENCIALIDADES DO CURRÍCULO POR PROJETOS PARA O ENSINO DE ENGENHARIA}

Nesse tópico, busca-se refletir e levantar implicações sobre a contribuição do currículo por projetos para a área da engenharia a partir da pesquisa apresentada em diálogo com produções acadêmicas que abordam o trabalho com projetos no ensino de Engenharia.

A formação dos engenheiros para a sociedade atual desafia as escolas de Engenharia a preparar os alunos não apenas com competência técnica, mas com habilidades de comunicação, trabalho em equipe e habilidades para solucionar problemas e de aprendizagem ao longo da vida.

As diretrizes curriculares para os cursos de Engenharia (CNE/CES, 2002), colocam como expectativa o seguinte perfil do formando egresso/profissional:

(...) o engenheiro com uma formação generalista, humanista, crítica e reflexiva, capacitado a absorver e desenvolver novas tecnologias, estimulando sua atuação crítica e criativa na identificação e resolução de problemas, considerando aspectos políticos, econômicos, sociais, ambientais e culturais com visão ética e humanista, em atenção às demandas da sociedade.

No entanto, são pouco presentes nos cursos de Engenharia organizações curriculares que otimizem o perfil proposto. Para Cunha (2015) a estruturação do currículo nas engenharias nem sempre é organizado de forma a alcançar os resultados esperados.

A organização do currículo em disciplinas estanques e sem uma integração entre os diversos componentes pode levar o estudante a compor um conhecimento fragmentado e, não raro, mantê-lo envolvido num conflito que 
requer o ajuste de tempo para atender às diversas demandas do curso, com prejuízos para o seu processo de aprendizagem (CUNHA, 2015 p.4).

Essa realidade pressiona a uma revisão dos modelos curriculares para os Cursos de Engenharia. Nesse cenário, desponta como uma alternativa propositiva o currículo por projetos.

Weenk e Blij (2011) defendem que a Aprendizagem Baseada em Projetos ou Project- Led Education (PLE) é uma abordagem que responde as mudanças da sociedade, do mundo do trabalho e das novas concepções de ensino e aprendizagem. Os autores propõem o PLEE, que é a denominação para o ensino de projetos na Engenharia. Segundo estes, os aspectos essenciais do projeto são a autenticidade de problemas reais relacionados a uma situação profissional, centrado nas atividades dos alunos trabalhando em equipe.

Na experiência sobre o Ensino de Engenharia Baseado em Projetos (PLEE) desenvolvida na Universidade de Twente, o projeto é uma parte essencial do currículo. Ele começa com um dia por semana e se expande até por quatro dias por semana. Trata de um problema representativo da prática profissional e é aberto a diversas soluções. O currículo é organizado de forma que cada período acadêmico tenha um tema representativo do curso. O projeto não é limitado a uma única disciplina (WEENK E BLIJ, 2011).

Os autores ao comparar os benefícios do PLEE com o ensino tradicional, salientam que não é uma comparação fácil pois são abordagens diferentes, mas destacam alguns ganhos como habilidades emocionais, habilidades acadêmicas e habilidades práticas.

Como principais desafios Weenk e Blij (2011) apresentam a crença dos professores e dos estudantes no ensino tradicional, é difícil convencer esses a mudar uma prática confortável, mesmo que insatisfatória. Destacam ainda como desafio o redesenho do currículo e equipamentos necessário para apoiar o PLEE. Ao alertar para o processo complexo que implica a mudança do currículo tradicional para o PLEE e destacam alguns cuidados para o sucesso na implementação, tais como: compreensão das razões da mudança; clareza de metas e procedimentos; liderança visível; apoio institucional; comunicação fluida entre os participantes; visualização das recompensas advindas com a mudança.

Fernandes, Flores e Lima (2010) trazem o caso dos cursos de Engenharia e Gestão Industrial na Universidade do Minho (MIEGI), que implantaram a partir de 2004 o trabalho com projetos interdisciplinares. Os autores apontam como motivos que levaram a adoção do PLE, o fato deste se mostrar como importante estratégia para o desenvolvimento de competências interdisciplinares, favorecendo a integração de conteúdos das várias disciplinas que participam no projeto, bem como, auxiliar na superação da compartimentalização do saber decorrente da divisão disciplinar, apresentando-se como alternativa para a insatisfação sentida pelos docentes com a fragmentação do ensino tradicional e as poucas possibilidades de interação que esse proporcionava entre professores e estudantes.

Os autores apresentam a experiência da implementação do PLE no $1^{\circ}$ ano do curso em que as unidades curriculares de Introdução à Engenharia e Gestão Industrial (IEGI), Programação de Computadores 1 (PC1), Química Geral (QG) e Cálculo C (CC) se integram em apoio ao projeto. Os projetos propostos permitem mais de uma solução e se baseiam em temas atuais e estimulantes tanto para os alunos como para os docentes.

A aplicação da metodologia PLE pressupõe trabalho em equipa por parte dos alunos para planear e realizar um projecto aberto que lhes é proposto, no qual desenvolvem as competências específicas das unidades curriculares de apoio directo ao projecto e competências transversais como as de realização de tarefas de forma cooperativa, monitorização do desenvolvimento do projecto, pesquisa e selecção de informação, negociação de conflitos e comunicação interpessoal (FERNANDES, FLORES E LIMA, 2010, p. 62).

Os estudantes trabalham em grupos formados entre seis a sete membros. Cada grupo é 
acompanhado por um tutor que monitora o andamento do projeto e o funcionamento da equipe, bem como interage com a equipe de coordenação do PLE e com os responsáveis pelo apoio pedagógico ao projeto.

A avaliação de caráter formativo se dá no processo por meio de vários pontos de acompanhamento (milestones) permitindo que os alunos obtenham o feedback dos docentes em diversas etapas do trabalho. Esses momentos de avaliação acontecem de diversas formas, tais como apresentações, entrega de relatórios, apresentações de protótipos, discussões em grupo e tutorias particulares de cada grupo com toda a equipe de coordenação do PLE.

Pesquisa realizada por Fernandes, Flores e Lima (2010) permite conhecer a perspectiva dos estudantes sobre o PLE e seus efeitos sobre a aprendizagem destes. A partir dos discursos dos alunos, foram levantadas as seguintes categorias: a articulação curricular, o desenvolvimento de competências transversais, o papel do professor e do aluno e, por fim, o processo de avaliação e os resultados acadêmicos.

Quanto a articulação curricular os alunos destacam o fator potencializador dos projetos para a integração das unidades curriculares já que para realizar o projeto precisam articular os conhecimentos das diversas áreas em uma situação prática, o que para eles torna o aprendizado mais estimulante ao mesmo tempo que desafia a busca autônoma dos conhecimentos. Os estudantes salientam a importância de atribuir sentido às aprendizagens, por meio de situações concretas ligadas à sua área profissional ou a vida real.

No entanto, alguns estudantes fizeram menção sobre a preferência pelo método tradicional por acharem que este não requer uma articulação e aplicação dos conhecimentos e pelo fato da avaliação ser exclusivamente baseada nos respectivos conteúdos lecionados. Os autores ponderam que essa visão dos estudantes está relacionada a uma visão mais acadêmica, mais preocupada com a aprovação do que a compreensão dos temas, bem como com a formação de habilidades transversais como trabalho em equipe, comunicação e outras.

Em relação ao desenvolvimento de competências transversais o PLE tem favorecido o desenvolvimento de um leque amplo de oportunidades. No contexto do trabalho com projetos os alunos enfrentam dificuldades especialmente com a gestão das atividades e com o relacionamento interpessoal. Na percepção destes, superar esses desafios auxilia a aquisição de competências para lidar com conflitos decorrentes de opiniões e objetivos divergentes, com posturas e atitudes de confronto e a comunicar-se no grupo. Aprendem ainda a organizar horário, cumprir prazos e planejar atividades e trabalhar em equipe.

No que diz respeito ao papel do aluno e do professor os testemunhos colhidos com os alunos apontam que os professores desempenham um papel mais ativo e mais reflexivo, tanto para adequar seu conteúdo para dar conta das demandas dos projetos dos alunos como para dar respostas às necessidades dos alunos durante o processo de realização. A relação professor e aluno também é mencionada pelos estudantes, destacam que é mais próximo e efetivo. Os alunos exercem um papel mais autônomo no gerenciamento da sua aprendizagem e desenvolvimento pessoal e profissional. Enfim, destacam a característica colaborativa e cooperativa no papel dos professores e dos alunos no contexto do PLE.

Quanto ao processo de avaliação realizada no PLE, os alunos apresentam diferentes significados. O cumprimento das atividades no decorrer do projeto (milestones) pressupõe um processo de avalição contínuo e formativo. Na visão de alguns isso é um aspecto positivo pois permite manter o empenho ao longo do projeto e o caráter aplicado e real do projeto favorece a predisposição para realização das atividades. Outros já fazem referências para a dificuldade de gerir o tempo com as atividades do projeto e os testes das unidades curriculares que não pertencem ao projeto. O PLE 
consome muito tempo. Outros contrastam com essa visão, considerando-a redutora, pois não estão preocupados só com os resultados, destacando que a avaliação PLE desenvolve outros tipos de competências que se processam em ambientes cooperativos, como o senso de responsabilidade e as habilidades de relacionamento e comunicação interpessoal.

Hattum Janssen (2011) realizou pesquisa com os professores que participaram dessa mesma experiência de implementação do PLEE nos cursos de Engenharia e Gestão Industrial na Universidade do Minho (MIEGI). A autora declara que a implementação de projetos na graduação produziu importantes mudanças nos paradigmas existentes no processo de ensino e aprendizagem. Na visão dos docentes pesquisados que participaram do programa, o PLEE apresentou as seguintes vantagens para a aprendizagem dos alunos:

1. Aprendizagem ativa: os professores não preparam os alunos com aulas teóricas, os estudantes têm que buscar responsavelmente por si mesmos os conhecimentos que precisam para desenvolver o projeto, dessa forma estudam desde o começo do curso e não apenas para os exames.

2. Interação: a abordagem colaborativa do trabalho com projetos promove um contato mais estreito entre alunos e entre alunos e professores.

3. Interdisciplinaridade: o desenvolvimento do projeto demanda a integração de diversas áreas do conhecimento contribuindo para a superação da fragmentação.

4. Formação profissional integrada com a realidade: os projetos favorecem a integração com problemas reais da Engenharia.

5. Competências transversais: além das competências técnicas, os alunos desenvolvem habilidades como liderança, habilidades de trabalhar em grupo, habilidades de se apresentar em público.

Andersen (2011) apresenta um programa, o EPS (European Project Semester) em que equipes de estudantes internacionais se juntam para trabalhar em projetos multidisciplinares. Dez universidades europeias implementaram esse programa em suas instituições (http://europeanprojectsemester.org).

Segundo o autor, os projetos geralmente são originários de situações reais do mundo do trabalho e em muitos casos desenvolvidos em cooperação com as empresas. Os alunos escolhem o projeto de acordo com seus interesses e motivações. Cada grupo é formado por cinco a seis estudantes com uma combinação interdisciplinar e internacional. Os projetos são da área da Engenharia, mas incluem elementos de Marketing, Negócios e Economia. " Dessa experiência, os estudantes retiram o que realmente significa trabalho em um contexto integrado" (ANDERSEN, 2011, p.40).

O autor conclui que os anos de trabalho com esse conceito de ensino tornam inconcebível pensar em voltar aos métodos anteriores. As avaliações sobre o trabalho realizado no EPS mostram que: os participantes desenvolvem percepção interdisciplinar; habilidades de comunicação e cooperação; alguns membros trabalham consideravelmente mais que o esperado; os estudantes assumem responsabilidade pelo próprio aprendizado; as habilidades profissionais são melhoradas, reforçadas e amadurecidas; o conhecimento, a capacidade de compreensão e a criatividade dos participantes aumenta (ANDERSEN, 2011).

Os dados da pesquisa realizada na UFPR litoral apontando a viabilidade da organização curricular por projetos se constituir em uma inovação no Ensino Superior em diálogo com as pesquisas acima relatadas sobre a aprendizagem baseada em projetos no ensino em engenharia, trazem repercussões potencializadoras para o ensino de Engenharia.

Uma das contribuições significativas do currículo por projetos para a inovação educativa em engenharia está na viabilização de uma abordagem interdisciplinar do conhecimento. A organização curricular tradicional, constituída por arranjos disciplinares compartimentalizados, não respondem à 
formação multidisciplinar esperada dos engenheiros para a solução dos problemas complexos da vida profissional. "O novo engenheiro deve ser capaz de propor soluções que sejam não apenas tecnicamente corretas, ele deve ter a ambição de considerar os problemas em sua totalidade, em sua inserção numa cadeia de causas e efeitos de múltiplas dimensões" (Parecer CNE/CES n. ${ }^{\circ}$ 1.362). Nesse contexto, o parecer citado propõe modos alternativos de organização curricular. "Ao lado da tradicional estrutura de disciplinas organizadas através de grade curricular, abre-se a possibilidade da implantação de experiências inovadoras de organização curricular". O currículo por projetos, enquanto uma das modalidades mais clássicas de integração curricular (SANTOMÉ, 1998) constitui-se numa via por excelência para promoção da formação interdisciplinar.

Outro ponto que consideramos significativo é superação da dicotomia teoria-prática e entre ciências básicas e profissionalizantes. Bringhenti (1993) em pesquisa realizada com egressos da Escola politécnica da Universidade de São Paulo, já denunciava que os estudantes nas etapas iniciais do curso viam muito pouco sobre engenharia, a abordagem das disciplinas é predominantemente teórica, os docentes das disciplinas básicas não fazem intersecção com a engenharia, os estudantes não percebem a aplicação desses conteúdos na continuidade do curso. A articulação da formação básica e profissionalizante proposta no currículo por projetos, oportuniza ao estudante de engenharia vivenciar e conhecer desde o início do curso as diversas áreas, favorecendo a descoberta vocacional e tornando o aprendizado mais significativo, contribuindo para a redução da evasão bastante usual nesses cursos. O contato do estudante com a prática profissional logo ao início do curso desperta para as exigências da profissão e estimula a atuação crítica e criativa no levantamento e resolução de problemas conforme perfil proposto nas Diretrizes Curriculares. A aprendizagem baseada em projetos defende a construção do conhecimento mediante uma prática pedagógica que tem a realidade como ponto de partida e de chegada, mediante procedimentos que levam a observar, problematizar, buscar, selecionar e analisar informações, elaborar propostas de intervenção, reconstruir e produzir conhecimento, em um movimento que integra teoria e prática, ciências básicas e profissionalizantes, aumentando a chances da obtenção de uma sólida formação acadêmica associada a uma larga experiência profissional.

Outro ganho observado no currículo por projetos, pouco presente nos currículos tradicionais e que promove habilidades profissionais esperadas dos engenheiros é o desenvolvimento de conhecimentos, habilidades e atitudes, ou ainda, competências transversais, que vão além da competência técnica.

O engenheiro do futuro deverá estar preparado para resolver vários tipos de problemas para trabalhar com tecnologias que ainda não existem e administrar empresas que estão surgindo a cada momento, além de ter habilidades de comunicação oral e escrita e trabalhar em equipe. Para tanto, ele deverá adquirir competências transversais, habilidades e atitudes coerentes associadas ao seu conhecimento técnico específico da área de atuação para soluções de problemas e projetos reais do cotidiano (CAMPOS, DIRANE E MANRIQUE, 2011).

De acordo com Moura e Barbosa (2006, p. 218, 219) “A proposta do ensino através de projetos representa uma forma importante de considerar todos os elementos da formação integral do ser humano. [...] Além disso, o processo favorece não apenas a aprendizagem de conceitos, mas ainda de procedimentos e atitudes em relação ao conhecimento e ao trabalho cooperativo".

Apresentam-se ainda como importantes desdobramentos do currículo por projetos favoráveis a uma nova abordagem no ensino de engenharia aspectos tais como: referenciais epistemológicos que valorizam a construção do conhecimento a partir de problematizações sociais concretas, abertura para a comunidade/sociedade como ambiente de problematização e aprendizagem, bem como, múltiplos domínios dos tempos e espaços e tecnologias. A qualidade que a profissionalidade em 
engenharia busca hoje exige uma pró-atividade que lhes permitam participar nos processos produtivos considerando seus aspectos políticos, econômicos, sociais, ambientais e culturais com visão ética e humanística em atendimento às demandas da sociedade conforme o perfil apontado nas Diretrizes Curriculares do Conselho Nacional de Educação. No entanto a formação em engenharia tem ficado muito restrita a esfera da universidade. A aproximação com contextos profissionais autênticos costuma ser reservada para os estágios nos anos finais do curso e as aprendizagens adquiridas nesses espaços dificilmente retornam para problematizações e reflexões nos momentos convencionais das aulas. Além do mais a ampliação dos espaços de aprendizagem mediante os estágios costumam ficar muito restritas ao setor produtivo. Em uma organização curricular por projetos ampliam-se consideravelmente os espaços incluindo-se também a comunidade, a realidade local e a sociedade mais ampla, levando o aluno a interagir com os contextos da realidade na busca de sólidas e sustentáveis soluções para as necessidades e problemas coletivos, favorecendo o exercício da profissão com compromisso social. Esse contato com a realidade social e profissional se dá desde o início do curso favorecida pela organização curricular por projetos, pois conforme Leite, Malpique e Santos (2001, p.57) "os projetos caracterizam-se como uma forma de articulação dos saberes escolares e dos saberes sociais”.

O estágio nos cursos de Engenharia também poderia assumir o formato de projetos. $O$ estágio ao mesmo tempo em que integra prática e teoria, colabora para que o aprendiz viva o ambiente, o cenário, os personagens, os grupos, os companheiros, o ambiente físico, os problemas e questões do dia a dia de sua profissão. Se assumimos a proposta de organizar os estágios no formato de projetos, define-se uma situação concreta que exige o encaminhamento de um problema de forma concreta e com intervenção na realidade. O projeto assume o processo e o produto: o diagnóstico do problema, a importância dos fundamentos teóricos para uma tomada de decisão, levantamento de hipóteses para a solução, por vezes trabalhos de laboratórios, maquetes, equacionamento das informações, análises de consequências das soluções possíveis, escolha de uma elas, justificativa teórica para a escolha feita, por fim, a aplicação da solução escolhida ao problema escolhido em seu contexto real e análise dos resultados obtidos. Necessita-se de criatividade, imaginação e fundamentação para encaminhar e realizar o projeto.

Os aspectos levantados sobre a relevância de uma organização curricular por projetos para os cursos de Engenharia não se esgotam, outros mais poderiam ser destacados como um movimento na direção de mudanças substanciais para o ensino de engenharia, tais como avaliação formativa, um novo contrato na relação e papéis de professores e alunos. Vale destacar que o trabalho com projetos adquire pertinência especial na área de engenharia ao considerar que esse é um campo profissional que se ocupa centralmente do processo de projetos. As diretrizes para os cursos de Engenharia fazem menção recorrente ao desenvolvimento de competências e habilidades de trabalhar com projetos: (...) II) projetar e conduzir experimentos e interpretar resultados/ III) conceber, projetar e analisar sistemas, produtos e processos; IV) planejar, supervisionar, elaborar e coordenar projetos e serviços de engenharia; XII) avaliar a viabilidade econômica de projetos em engenharia(...) (Art. $4^{\circ}$, Resolução $N^{\circ}$ 11/2002). Tais orientações chamam atenção para o fato das graduações oferecerem atividades que pouca aplicação tem fora das instituições de ensino, enquanto na vida pós-escolar estarão de alguma forma envolvidos com projetos.

A combinação do trabalho com projetos na educação com os fundamentos da formação para projetos na engenharia tem o potencial de contribuir para a criação de novos cenários e panoramas de formação mais profissionais e eficazes para responder às novas condições e necessidades da sociedade onde vão exercer sua profissão e para conquistar uma melhor qualidade de vida. Trata-se de formar uma profissional competente, bem como um cidadão crítico, sujeito histórico, criativo, com iniciativa para problematizar e transformar os contextos e as relações nos quais está inserido.

\section{CONSIDERAÇÕES FINAIS}

O presente estudo buscou analisar o potencial de um currículo por projetos para uma inovação na educação superior e para o ensino de engenharia. Para tal, primeiramente se apresentou os 
resultados de uma pesquisa qualitativa realizada na Universidade Federal do Paraná- Campus Litoral sobre o currículo por projetos no Ensino Superior. Os dados apontam para a contrubuição inovadora do currículo por projetos ao ser capaz de articular um conjunto de elementos considerados como relevantes para uma nova cultura de ensino/aprendizagem na Educação Superior, tais como: relação entre teoria e prática, interdisciplinaridade, múltiplos domínios de espaços, tempos e tecnologias; relação de parceria entre professor e aluno; referenciais epistemológicos que valorizam a construção do conhecimento a partir de problematizações sociais concretas e abertura para a comunidade/sociedade como ambiente de problematização e aprendizagem (KELLER-FRANCO, 2008, 2012).

Na sequência, busca-se refletir e levantar implicações sobre a contribuição do currículo por projetos para a área da engenharia a partir das pesquisas e produções acadêmicas que abordam a aprendizagem baseada em projetos nessa área. Os estudos, parte deles denominam a aprendizagem com projetos como PLEE - Aprendizagem baseada em Projetos no Ensino de Engenharia, apresentam como contributos: aprendizagem significativa, ativa e autônoma, com responsabilidades compartilhadas; relações cooperativas; interdisciplinaridade e articulação de unidades curriculares; aprendizagem por meio de situações reais e contextualizadas; avaliação formativa e o desenvolvimento de competências transversais, como por exemplo, relacionamento interpessoal, trabalho em equipe, capacidade de comunicação oral e escrita, resolução de conflitos, gestão e organização do tempo, planejamento, dentre outras.

A pesquisa relatada nesse artigo sobre o currículo por projetos no ensino superior em diálogo com as pesquisas na área da engenharia sugere que esta proposta curricular se descortina como um arranjo superador da lógica disciplinar-fragmentária e abstracionista, ao se orientar na lógica da integração dos conhecimentos a partir de situações concretas extraídas da realidade em toda a sua complexidade.

O presente estudo apresenta o currículo por projetos como uma alternativa inovadora na educação superior e no ensino de engenharia, mas, não oculta desafios. Conforme nos lembra Castanho (2000, p.90) "é relativamente fácil introduzir mudanças superficiais que não ameacem as estruturas existentes. Desafiar e mudar as estruturas profundas do ensino constituem o grande desafio". Na busca de caminhos possíveis, e, ao mesmo tempo comprometidos para alavancar e alterar estruturas enraizadas do ensino, não podem ser desconsiderados aspectos tais como: apoio institucional, clima organizacional, processo de planejamento participativo, formação de professores, flexibilidade do programa e dos atores para correções e construções emergentes no processo, comunicação aberta com os envolvidos como alunos, pais e comunidade, bem como, os fatores macro estruturais e seus determinantes sociopolíticos, econômicos e culturais, como por exemplo as regulações externas que se avolumam no Ensino Superior, dentre tantos outros.

No entanto, tais dificuldades podem ser superadas pelo planejamento cuidadoso incluindo um plano de visão e de ação bem fundamentado e pelo valor adicional do paradigma curricular integrado sobre o paradigma tradicional para responder aos desafios da atualidade.

No Brasil ainda são pouco comuns experiências com a abordagem de projetos seja como metodologia ou paradigma curricular. Em âmbito internacional o trabalho com projetos vem se firmando como uma importante mudança no campo da educação, em especial nas engenharias. Dessa forma, o currículo com projetos abre-se como uma temática relevante para outras pesquisas.

\section{REFERÊNCIAS}

ANDERSEN, A. A. Fórmula EPS - Projeto Semestral Europeu. In: CAMPOS, L. C.; DIRANI, E.A.T; MANRIQUE, A. L. (orgs). Educação em Engenharia: novas abordagens. São Paulo: Educ, 2011.

BEANE, A. J. Integração curricular: a essência de uma escola democrática. Currículo sem fronteiras, v.3, n.2, p.91-110, jul./dez. 2003. 
BEHRENS, M. A. A interconexão da metodologia de projetos com utilização de recursos informacionais num paradigma da complexidade. In: ENDIPE, 2004, Curitiba: Anais do ENDIPE, 2004, 2 v.

BERNSTEIN, Basil. Estruturação do discurso pedagógico: Classe, Códigos e controle. Petrópolis: Vozes, 1995.

BOUTINET, J. P. Antropologia do projeto. Porto Alegre: Artmed, 2002.

BRASIL. Diretrizes Curriculares Nacionais do Curso de Graduação em Engenharia. Resolução CNE/CES n. 11, de 11 de março de 2002.

BRINGHENTI, I. O ensino na Escola Politécnica da USP: fundamentos para o ensino de Engenharia. São Paulo: EPUSP, 1993.

BRUNNER, J. O Processo da Educação. Editora Nacional, São Paulo: 1976.

CAMPOS, L. C.; DIRANI, E.A.T; MANRIQUE, A. L. (orgs). Educação em Engenharia: novas abordagens. São Paulo: Educ, 2011.

CASTANHO, M. E. Professores e inovações. In: CASTANHO \& CASTANHO (Orgs.). O que há de novo na educação superior: do projeto pedagógico à prática transformadora. Campinas: Papirus, 2000.

CUNHA, F.M. Ensino de Engenharia: abordagem pela complexidade. Revista de Ensino de Engenharia, v. 34, n. 1, p. 3-16, 2015.

DEWEY, J. Como pensamos. 3. ed. Tradução de Haydée de Camargo Campos. São Paulo: Companhia Editora Nacional, 1959.

FERNANDES, S. R.; FLORES, M. A.; LIMA, R.M. A Aprendizagem Baseada em Projetos

Interdisciplinares: avaliação do impacto de uma experiência no ensino de engenharia. Avaliação, Campinas, SP, V. 15, n.3, p. 59-86, nov. 2010.

HATTUM-JANSEM, N. V. A avaliação dos alunos no contexto de um projeto interdisciplinar. In: CAMPOS, L. C.; DIRANI, E.A.T; MANRIQUE, A. L. (orgs). Educação em Engenharia: novas abordagens. São Paulo: Educ, 2011.

HERNADEZ, F. Transgressão e mudança na educação: os projetos de trabalho. Porto Alegre: Artmed, 1998.

KELLER-FRANCO, E. Currículo por projetos: inovação do ensinar e aprender na educação superior. Dissertação (mestrado em Educação: currículo) - Pontifícia Universidade Católica de São Paulo, 2008.

KELLER-FRANCO, E . Inovação na educação superior: o currículo por projetos. In: MASETTO, Marcos T. Inovação no ensino superior. São Paulo. Loyola, 2012.

KNIGHT, G. R. Filosofia \& educação. Engenheiro Coelho, SP, Imprensa Universitária Adventista, 2001.

LEITE, E.; MALPIQUE, M.; SANTOS, M. R. Trabalho de projecto: aprender por projectos centrados em problemas. 4. ed. Porto: Afrontamento, 2001.

LOPES, Alice Casimiro; MACEDO, Elizabeth. Teorias de Currículo. São Paulo: Cortez, 2011.

MASETTO, M. T. (org). Inovação no Ensino Superior. São Paulo, Loyola, 2012.

MASETTO, M. T. Inovação Curricular no Ensino Superior. e-curriculum, vol.7, nº 2, 2011.

MASETTO, M. T . PBL na Educação? In: ENDIPE, Curitiba: Anais do ENDIPE, v.2, 2004.

MOESBY, E. Reflections on making a change towards projects oriented and problem- based learning. World Transactions on Engineering and Technology Education, Aalborg, Dinamarca, vol.3, n.2, 2004.

MOURA, D. G.; BARBOSA, E. F. Trabalhando com projetos: planejamento e gestão de projetos educacionais. Petrópolis: Vozes, 2006.

SANTOMÉ, J. T. Globalização e interdisciplinaridade: o currículo integrado. Porto Alegre: Artes Médicas, 
ISSN 1983-1579

Doi: 10.22478/ufpb.1983-1579.2018v1n11.28548

http://periodicos.ufpb.br/ojs2/index.php

1998.

SILVA, T. T. Documentos de identidade: uma introdução às teorias do currículo. 2. ed. Belo Horizonte: Autêntica, 2007.

WEENK, W.; BLIJ, M.B.V. A Metodologia PLEE e as experiências na Universidade do Twente. In: CAMPOS, L. C.; DIRANI, E.A.T; MANRIQUE, A. L. (orgs). Educação em Engenharia: novas abordagens. São Paulo: Educ, 2011.

ZABALZA, M. A. O ensino universitário: seu cenário e seus protagonistas. Porto Alegre: Artmed, 2004.

Recebido em: 16/04/2016

Alterações recebidas em: 25/03/2018

Aceito em: 26/03/2018

Publicado em: 26/04/2018 